See Article page 233.

\section{Commentary: Road maps, dominos, and awe}

\section{Elizabeth H. Stephens, MD, PhD}

The complexities of congenital heart disease make the specialty challenging, creative, and certainly never boring. Whether that be examining the tricuspid valve and how it interacts with a ventricular septal defect, which is unique to each patient, or aspects of an atrioventricular septal defect, under each "umbrella" of a diagnostic label there is vast diversity that we experience every day.

In the case report presented by Cleuziou and colleagues, ${ }^{1}$ we read of a patient with a right juxtaposed left atrial appendage discovered intraoperatively at the time of ventricular septal defect repair. This patient is unique first because of the right juxtaposed left atrial appendage, but more profoundly, given the context, because this anomaly occurred concomitant with a relatively "simple" intracardiac lesion of a ventricular septal defect, as opposed to more complex lesions that are more commonly associated with juxtaposed appendages.

While this report could be written off as merely a novelty, it highlights two important points: first, the importance of road maps and second, the breathtaking complexity of development. In the particular case reported, the juxtaposed appendage had little bearing on the surgery; however, such anomalies can have critical clinical implications. In complex lesions, the position of the atrial appendages and their relationship with the atrium and downstream ventricles can be challenging to decipher, particularly intraoperatively and/or in the setting of an emergent situation. Just such a patient was in our unit recently. Given the patient's complexity, the cardiac computed tomography scan was carefully reviewed to plan how the patient would be

From the Department of Cardiovascular Surgery, Mayo Clinic, Rochester, Minn. Disclosures: The author reported no conflicts of interest.

The Journal policy requires editors and reviewers to disclose conflicts of interest and to decline handling or reviewing manuscripts for which they may have a conflict of interest. The editors and reviewers of this article have no conflicts of interest.

Received for publication April 8, 2021; revisions received April 8, 2021; accepted for publication April 12, 2021; available ahead of print April 16, 2021.

Address for reprints: Elizabeth H. Stephens, MD, PhD, Department of Cardiovascular Surgery, Mayo Clinic, 200 First St SW, Rochester, MN 55905 (E-mail: stephens. elizabeth@mayo.edu).

JTCVS Techniques 2021;7:238-9

2666-2507

Copyright (C 2021 The Author(s). Published by Elsevier Inc. on behalf of The American Association for Thoracic Surgery. This is an open access article under the CC BY-NC-ND license (http://creativecommons.org/licenses/by-nc-nd/4.0/).

https://doi.org/10.1016/j.xjtc.2021.04.011

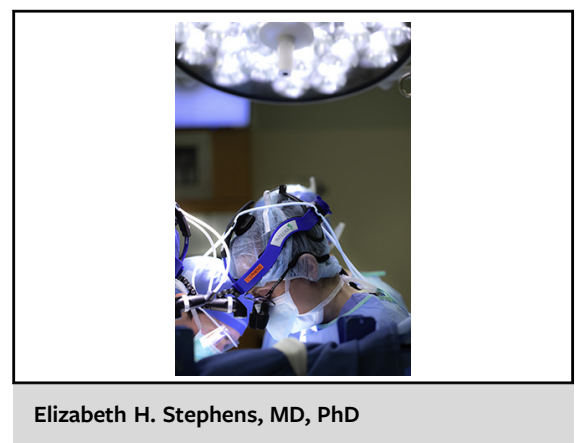

CENTRAL MESSAGE

This case report of a right juxtaposed left atrial appendage with a ventricular septal defect highlights the importance of creating road maps for surgeons and emphasizes the complexity of development.

cannulated should emergent extracorporeal membrane oxygenation be necessary.

Secondly, the case report highlights the intricate path through which the embryo tiptoes to end up with what is considered anatomically normal the vast majority of the time, and how little we know about this process. As alluded to earlier, this atrial appendage juxtaposition was not accompanied by other major congenital cardiac anomalies. In syndromes like heterotaxy, a step in development is perturbed, and a cascade of reactions ensue, resulting in a number of related anomalies, much of which is still unknown. ${ }^{2}$ Similarly, in hypoplastic left heart syndrome, depending on when in development a perturbation occurs, resulting processes are all impacted that seem to explain the constellation of anatomic findings. ${ }^{3}$ As we have uncovered more and more congenital heart defects, we begin to appreciate the countless necessary steps of development; at each of these steps a problem can occur, leading to a seemingly endless array of alternative configurations that the congenital heart surgeon is tasked to reroute in a corrective or palliative manner. And yet, in this case, the proverbial row of dominoes set up leaning on one another was disturbed with only one domino falling. And this just adds to the awestruck wonder of being a congenital heart surgeon. 
"The most beautiful thing we can experience is the mysterious. It is the source of all true art and science. He to whom this emotion is a stranger, who can no longer pause to wonder and stand rapt in awe, is as good as dead: his eyes are closed"

-Albert Einstein

\section{References}

1. Cleuziou J, Kemmer J, Sauer U, Pringsheim M. Juxtaposition of the atria appendages in a patient with a simple ventricular septal defect. J Thorac Cardiovasc Surg Tech. 2021;7:233-5.

2. Desgrange A, Le Garrec JF, Meilhac SM. Left-right asymmetry in heart development and disease: forming the right loop. Development. 2018;145:dev162776.

3. Stephens EH, Gupta D, Bleiweis M, Backer CL, Anderson RH, Spicer DE. Pathologic characteristics of 119 archived specimens showing the phenotypic features of hypoplastic left heart syndrome. Semin Thorac Cardiovasc Surg. 2020;32:895-903. 